\title{
Comparative Study on Open and Closed Drainage in Emergency Laparotomy
}

\author{
${ }^{1}$ Dr.V.T.Arasu, ${ }^{2}$ Dr.Rajarajan Kamaraj, \\ ${ }^{l}$ Associate professor, Department of general surgery, Government thiruvannamalai medical college, \\ Thiruvannamalai, Tamil nadu. \\ ${ }^{2}$ Assistant civil surgeon, Government head quarters hospital, Ariyalur, Tamil nadu.
}

\begin{abstract}
:
Background: Drains are routinely used after major abdominal surgeries to drain intraperitoneal collections, and to drain the fluid or blood collected in the peritoneal cavity after surgeries

Methods: Prospective study on patients undergoing emergency laparotomies for acute abdomen in Department of General surgery, Chengalpattu medical college are placed open and closed drains, are followed up with necessary investigations.
\end{abstract}

Result: In our study 30 emergency laparotomies open drainage with corrugated rubber drain and 30 emergency laparotomies closed tube drains were placed and the results were compared

Conclusion: The incidence of infection, pain, hospital stay, post operative morbidity is not significantly altered in open and closed drainage system.

Keywords: drain, laprotomy, drain removal

\section{Introduction}

Emergency laparotomy is required for major intra-abdominal haemorrhage spontaneous or due to abdominal trauma and for infective, ischemic and obstructive condition in which gastric intestinal wall as a barrier is breached or threatened.[1][2]

Exploratory laparotomy is carried out in conditions where the need for an operation is recognized but where a definite diagnosis can be made only until the abdomen is opened.

\section{Aims And Objectives}

A prospective study to compare the usage of open and closed drains, fluid drained, complications postoperative morbidity and hospital stay in emergency laparotomy in department of General Surgery, Chengalpattu medical college, Chengalpattu.

\section{Materials And Methods}

Prospective study on patients undergoing emergency laparotomies for acute abdomen in Department of General surgery, Chengalpattu medical college are placed open and closed drains are followed up with necessary investigations.

Collected data is used to compare open and closed drains fluid drained, complications, postoperative morbidity and hospital stay.

\section{Inclusion criteria;}

- All acute abdomen (blunt injury, peritonitis, bowel strangulation / obstruction) cases attending our institution.

- $\quad$ Age > 18 yrs and <70yrs.

- Laparotomy which were approached by midline incision.

- Prolene 1'0 was used universally for rectus closure by continuous locking sutures.

- 2'0 Vicryl was the absorbable suture which was used for anastomosis.

- Urinary catheterization was routinely done for all cases.

- Prolene 3'0 used for approximation of skin by interrupted sutures

- Patients are randomly divided in to two groups and one group is placed closed drain (tube drain) and other group is placed open drain ( corrugated rubber drain)

Exclusion criteria;

- $\quad$ Age <18yrs

- Pregnant women

- Lactating mothers 
- Female patients with gynecological disease

- Acute abdomen managed by conservative methods

\section{Indications}

- To remove existing collection of blood or pus

- To prevent build up of normal body fluids

- To prevent potentially life threatening complications

\section{Passive Drains}

The pressure difference between inside and outside the wound along with capillary action and gravity forces the fluid out of the wound.[3][4]

\section{Open Drain}

Drains provide a conduit through which fluids drain .eg Corrugated rubber drain Penrose drain Sump drain

\section{Closed Drain}

Closed drains act by capillary action or by gravityeg. Robinson tube drain Intercostal chest tube Ventriculo peritoneal shunt

\section{Active Drains}

Active drains are connected to a reservoir and exerts a negative force. The fluid is drained in exchange for negative pressure. The system fails to drain once the vaccum is lost.[5][6][7]

\section{High Pressure System}

Bottled vaccum devices. Redivac

II. Low Pressure System

Jackson pratt

4 channel vaccum devices. Eg. J VAC, Blakes

\section{Drain Insertion}

Drains commonly inserted at the end of surgical procedure.

Drains inserted from a separate stab incision and not from the main wound.

- when the drain is attached with the trocar : the trocar is used to pierce the wound from inside, the drainage tube is brought from inside of the wound, the trocar is detached and stay suture is used to fix the drain. The drain is connected to suction apparatus only after closure of the wound.[8][9]

- when the drain is not attached to the trocar: The surgeon uses the forceps to pierce the abdominal wall from inside, and a small nick is made in the skin with the scalpel and the drain is brought from outside.The drain is fixed to the skin with stay sutures.

\section{Removal Of Drains}

The time to remove a drain varies with the fluid to be drained.

- Draining blood[md] 48 to 72 hours.

- Draining down to a suture line[md]5 to 7 days.

- Draining a septic cavity[md]until pus ceases to flow, usually in 5 to 7 days.

- Don't leave a drain in longer than is necessary, because you run the risk that it may erode a vessel. There is seldom any need to leave a drain more than a week at the most, except in a very large deep abscess, as in the subphrenic space, where you may need to leave one in for 10 days. If you remove a drain too early, pus may build up and seek to discharge itself elsewhere.[10][11]

If a drain is long, shorten it progressively over several days before you remove it. Shorten it by pulling it out, not by cutting it off. Place a safety pin through it and tape this to the patient's skin.

\section{Ray Chest \& Abdomen}

\section{INVESTIGATIONS}

- Fracture lower ribs show that there has been an injury which has the potential to damagethe liver or spleen,

- Pelvic fractures indicate potential injury to pelvic organs.

- Obliteration of a psoas shadow, and fractures of the bodies, or transverse processes, of the upper lumbar vertebrae are markers of significant retroperitoneal trauma.

- The X-ray may show a diaphragmatic rupture, or it may demonstrate free 
- $\quad$ intraperitoneal or retroperitoneal gas, thus confirming a breach in the gastrointestinal tract.

Intravenous Urogram (Ivu) provides some assessment of the severity of the damage to a kidney, but more importantly confirms both the presence and thefunction of the contralateral kidney.

\section{CT Scanning}

- Excellent modality for imaging solid organs and the retroperitoneum.

- Contrast CT gives valuable information not only on the anatomical damage to the liver, spleen, kidney or pancreas, but also information on renal function, major vessel damage and the presence of arterial bleeding intoa haematoma.

- Better modality than an IVU in renal trauma.

- Serial CT appearance of solid organ damage is an increasingly useful predictor of the untreated outcome of an injury, and thus influences the balance between laparotomy and continued conservative management. [12][13]

- It may also indicate situations where it is possible to stop the haemorrhage by selective embolization, and avoid surgical intervention. Embolization occludes the vessels at the site of haemorrhage, whereas surgical ligation ofthe main feeding artery does not take into account any additional collateral inflow.

\section{Peritoneal Lavage}

A small open incision under local anaesthesia is now preferred.This makes the procedure more invasive, more difficult in the obese, and less applicable in a child who may not tolerate it under local anaesthesia. More information will be obtained by a laparoscopy which in turn is even more invasive.

The concept of peritoneal lavage overlooks the potential for bleeding to be self-limiting, and many surgeons believe it leads to unnecessary intervention if laparotomy automatically follows a 'positive' test for red blood cells (RBCs).[14][15]

A 'positive' test for white blood cells (WBCs) is more significant as it indicates peritoneal contamination from damage to the gastrointestinal tract.

The patient should already have a nasogastric tube and urinary catheter in situ before a diagnostic peritoneal lavage is undertaken.

A 5-cm vertical incision is made under local anaesthetic, centred one-third of the way from umbilicus to xiphisternum, and is deepened down to peritoneum, which is then incised under direct vision.[16]

A dialysis catheter is inserted and $10 \mathrm{~mL} / \mathrm{kg}$ body weight of warmed normal saline (to a maximum of 1 L) is run into the peritoneal cavity. After 5-10 minutes the lavage solution is drained and examined microscopically.[17]

\section{A 'positive' result is:}

- $\quad$ RBCs $>100000$ per $\mathrm{mL}$; or

- $\quad$ WBCs $>500$ per $\mathrm{mL}$.

- Gut contents visible on microscopy, or a Gram stain whichdemonstratesbacteria, also demonstrate a breach of the gastrointestinaltract.

\section{Laparotomy For Trauma}

Significant intra-abdominal trauma can sometimes be managed more appropriately in a non-operative manner.

In cases where the surgeon decides on an emergency laparotomy, consideration must be given to other potential injuries. Forexample

- An apparently minor chest injury with an undetected small pneumothorax, may convert to a tension pneumothorax from the positive-pressure ventilation during a laparotomy. A chest drain should be inserted prior to induction of anaesthesia if this is felt to be a risk.

- An associated head injury must not be overlooked, and neurological monitoringwill be difficult during anaesthesia.

- If a cervical spine injury cannot be excluded, the neck must be adequately immobilized during the laparotomy.

- A midline incision is the most appropriate in almost every circumstance in which an emergency laparotomy is indicated. Blood, or intestinal contents, may be encountered on opening the peritoneum, but a 'clean' peritoneal cavity doesnot exclude a significant injury.

- A perforation can easily be missed, and a careful inspection of the whole gastrointestinal tract is essential.

- A large collection of blood usually indicates damage to the spleen or liver, or to a vessel in the mesentery or omentum.

- The first priority is haemorrhage control, followed by a thorough exploration to evaluate other injuries. 
Complications Of Laparotomy

- Seroma

- Hematoma

- $\quad$ Surgical site Infection (superficial and deep infecton)

- Wound dehiscence

- Stitch abscess

- Wound evisceration

- Incisional hernia

- Unsighly scar.

VI. Results

Age Wise Distribution Of Closed And Open Drains

\begin{tabular}{|l|l|l|l|l|l|l|}
\hline Drain & open & closed & Total & chi sq & p value & \\
\hline $20-40$ & 16 & 19 & 35 & 0.6 & 0.4 & not significant \\
\hline $41-60$ & 14 & 11 & 25 & & & \\
\hline & 30 & 30 & 60 & & & \\
\hline
\end{tabular}

Sexwise Distribution Of Open And Closed Drains

\begin{tabular}{|l|l|l|l|l|l|l|}
\hline Drain & open & closed & Total & chi sq & p value & \\
\hline male & 27 & 24 & 51 & 1.18 & 0.2 & not significant \\
\hline female & 3 & 6 & 9 & & & \\
\hline & 30 & 30 & 60 & & & \\
\hline
\end{tabular}

Mean Age In Open And Closed Drains

\begin{tabular}{|l|l|}
\hline Drain & Mean Age \\
\hline open & 41.4 \\
\hline closed & 38.63 \\
\hline
\end{tabular}

Fluid Drained Open

\begin{tabular}{|l|l|}
\hline & open \\
\hline pod1 & $4.53 \mathrm{G}$ pads \\
\hline pod2 & $2.7 \mathrm{G}$ pads \\
\hline pod3 & $1.23 \mathrm{G}$ pads \\
\hline
\end{tabular}

Fluid Drained Closed

\begin{tabular}{|l|l|}
\hline & closed \\
\hline pod1 & $356.67 \mathrm{ml}$ \\
\hline pod2 & $225.33 \mathrm{ml}$ \\
\hline $\operatorname{pod} 3$ & $118.33 \mathrm{ml}$ \\
\hline
\end{tabular}

Infection Results In Open And Closed Drains

Infection Vs Drain

\begin{tabular}{|l|l|l|l|l|l|l|}
\hline Drain & open & closed & Total & chi sq & p value & \\
\hline nil & 18 & 23 & 41 & 1.93 & 0.1 & not significant \\
\hline yes & 12 & 7 & 19 & & & \\
\hline & 30 & 30 & 60 & & & \\
\hline
\end{tabular}

Results Of Soakage In Open And Closed Drains

Sokagevs Drain

\begin{tabular}{|l|l|l|l|l|l|l|}
\hline Drain & open & closed & Total & chi sq & p value & \\
\hline nil & 1 & 29 & 30 & 52.27 & $\mathbf{0 . 0 0}$ & significant \\
\hline yes & 29 & 1 & 30 & & & \\
\hline & 30 & 30 & 60 & & & \\
\hline
\end{tabular}

Results Of Pain Due To Drains

Pain Vs Drain

\begin{tabular}{|l|l|l|l|}
\hline Drain & open & closed & Total \\
\hline nil & 18 & 18 & 36 \\
\hline
\end{tabular}




\begin{tabular}{|l|l|l|l|}
\hline yes & 12 & 12 & 24 \\
\hline & 30 & 30 & 60 \\
\hline
\end{tabular}

Results Of Causes Of Emergency Laparotomy Diagnosis

\begin{tabular}{|c|c|c|c|}
\hline Drain_R & & Frequency & Percent \\
\hline \multirow[t]{11}{*}{ open } & ADHESIVE OBSTRUCTION & 1 & 3.3 \\
\hline & APPENDICULAR ABSCESS & 4 & 13.3 \\
\hline & BLUNT INJURY ABDOMEN & 2 & 6.7 \\
\hline & DU PERFORATION & 12 & 40 \\
\hline & GASTRIC PERFORATION & 2 & 6.7 \\
\hline & ILEAL PERFORATION & 2 & 6.7 \\
\hline & INTESTINAL OBSTRUCTION & 4 & 13.3 \\
\hline & OBSTRUCTED HERNIA & 1 & 3.3 \\
\hline & PENETRATING INJURY ABDOMEN & 1 & 3.3 \\
\hline & SUBACUTE OBSTRUCTON & 1 & 3.3 \\
\hline & Total & 30 & 100 \\
\hline \multirow[t]{10}{*}{ closed } & ADHESIVE COLIC & 1 & 3.3 \\
\hline & APPENDICULAR ABSCESS & 2 & 6.7 \\
\hline & BLUNT INJURY ABDOMEN & 3 & 10 \\
\hline & DU PERFORATION & 14 & 46.7 \\
\hline & GASTRIC PERFORATION & 2 & 6.7 \\
\hline & ILEAL PERFORATION & 3 & 10 \\
\hline & INTESTINAL OBSTUCTION & 3 & 10 \\
\hline & SIGMOID VOLVULS & 1 & 3.3 \\
\hline & STAB INJURY & 1 & 3.3 \\
\hline & Total & 30 & 100 \\
\hline
\end{tabular}

\section{Mean Hospital Stay}

\begin{tabular}{|l|l|}
\hline Drain & Mean stay \\
\hline open & 10.97 \\
\hline closed & 10.3 \\
\hline
\end{tabular}

\section{Discussion}

- There is insufficient evidence from randomised controlled trials (RCTs) to support the routine use of closed suction drainage in general surgery (emergency surgery). Further RCTs with larger patient numbers are required for different operations before definite conclusions can be made for all types of operations. [18][19][20]

- Despite the paucity of clinical evidence demonstrating any benefit supporting their use, drains continue to be placed after emergency procedures.[21][22]

- The routine use of drains may be abandoned in uncomplicated thyroid surgery.[23]

- The optimal time to remove drains after abdominal surgery varies.

- Pelvic drainage may act as an early detector of anastomotic leaks and reduce the need for re-operation in selected patients undergoing rectal cancer surgery. [24][25].However, others consider that leaks usually occur after drains have been removed and that they are not useful in this way.

- Drain use after elective laparoscopic cholecystectomy increases wound infection rates and delays hospital discharge.[26] Evidence to support the use of drain after the following procedures could not be found:

1. Laparoscopic cholecystectomy

2. Open cholecystectomy

- Evidence for drains reducing infection and haematoma formation after breast surgery is inconsistent.[27]

- Many gastrointestinal operations can be performed safely without prophylactic drainage. Drains should be omitted after hepatic, colonic or rectal resection with primary anastomosis and appendectomy for any stage of appendicitis.[28][29]

- A retrospective review found that even the complicated appendicitis (with secondary peritonitis and sepsis) in the modern era of antibiotics does not necessitate the use of prophylactic drain placement which, at times, may even prove counterproductive. [30]

- Prophylactic drainage is indicated after oesophageal resection and total gastrectomy. For many other gastrointestinal procedures (especially involving the upper gastrointestinal tract) there is a need for more research to clarify the value of prophylactic drainage.[31]

- There is insufficient evidence showing that routine drainage after colorectal anastomoses prevents anastomotic and other complications. Damage may be caused by mechanical pressure or suction and drains may even induce an anastomotic leak.[32]

- Drains are not a substitute for good surgical technique. 
- In our study 30 emergency laparotomies open drainage with corrugated rubber drain and 30 emergencylaparotomies closed tube drains were placed and the results were compared.

- Emergency Laparotomies were common in 20-40 years age group which constitutes 58\% ,aand 41-60 years constitutes $42 \%$ of laparotomies.

- The incidence of emergency laparotomy was higher in males .M:F ratio is $5.5: 1$

- Amount of fluid drained can be measured well in closed drainage but can be measured by number of pads soaked in open drainage.

- Mean age of open drainage is 41.4 years and closed drainage is 38.6

- Infection rates were slightly higher in open drainage with $40 \%$ and closed drainage is $15 \%$ but $p$ value is 0.1 and stastically not significant

- The incidence of wound soakage and patient discomfort is higher in open drainage system.

- The incidence of pain is equally distributed in both the groups

- The mean hospital stay is 10.93 days in open drainage and 10.3 in closed drainage

\section{Conclusion}

From the above mentioned study in emergency laparatomies we came to the conclusion that the incidence of infection, pain, hospital stay, post operative morbidity is not significantly altered in open and closed drainage system.

\section{Bibliography}

[1]. Surgical Vacuum Drains:Types, Uses, and Complications Rajaraman Durai, Md, Mrcs; Philip C.H. Ng, Md, Frcs

[2]. M\& M Drains: Irish Medical Journal. June 2001

[3]. Memon MA, Memon MI, Donohue JH; Abdominal drains: a brief historical review. Ir Med J. 2001 Jun;94(6):164-6.

[4]. Price.J. Drainage in abdominal surgery Tr Am ass OBG 1; 84-92

[5]. Smith SR, Gillmore OJ. Surgical drainage. Br J Hosp med1985

[6]. Levy M. Intraperitoneal drainage. American journal of Surgery 1984

[7]. Moss JP. Historical and current perspectives on surgical drainage surg gynaecology 1981;152

[8]. Hosgood G. The history of surgical drainage. J Am Med Asso 1990

[9]. Robinson JO surgical drainage historical perspective 1986

[10]. Wangesteen OH, Wangesteen SD, Rise of surgery 1978

[11]. Mumford JG: Surgical memoirs and other essays, New York Yates JL; local effects of peritoneal drainage. Br J Surg 1905

[12]. Rockwood CA Jr. Chambers, South Med journal 1987 498-501

[13]. Makama JG, Ameh EA; Surgical drains: what the resident needs to know. Niger J Med. 2008 Jul-Aug;17(3):244-50.

[14]. Memon MA, Memon B, Memon MI, et al; The uses and abuses of drains in abdominal surgery. Hosp Med. 2002 May;63(5):282-8.

[15]. Drowning in drainage : Quinton de cock American journal of trauma Surgical Drains, Caths, Tubes and Central Lines: Al-Momtan, Ahmed T.

[16]. Rees VL, Coller FA: Anatomic and clinical study of the transverse Abdominal incision. Archives of surgery 1943;47:136-146

[17]. Axer H, Keyserlingk DG, Prescher A: Collagen fibers in linea alba and rectus sheaths. I. General scheme and morphological aspects. J Surg Res 2001;96:127-134

[18]. Nahai F, Brown RG, Vasconez L: Blood supply to the abdominal wall as related to planning abdominal incisions. Am Surg 1976;42:691-695

[19]. Klinge U, Prescher A, Klosterhalfen B, Schumpelick V: (Development and pathophysiology of abdominal wall defects). Chirurg 1997;68:293-30

[20]. Guillou PJ, Hall TJ, Donaldson DR, Broughton AC,Brennan TG: Vertical abdominal incisions - a choice? Br J Surg1980;67:395399

[21]. Lip: De dwarse en vertikaleincisie van de bovenbuikbijgalblaasoperaties. Thesis, Rotterdam, 1981

[22]. Kendall SW, Brennan TG, Guillou PJ: Suture length to wound length ratio and the integrity of midline and lateral paramedian incisions. Br J Surg 1991;78:705-707.

[23]. Hodgson NC, Malthaner RA, Ostbye T: The search for an ideal method of abdominal fascial closure: a meta-analysis. AnnSurg 2000;231:436-442.

[24]. Mudge M, Hughes LE: Incisional hernia: a 10 year prospective study of incidence and attitudes. Br J Surg 1985;72:70-71. Luijendijk RW, Jeekel J, Storm RK, Schutte PJ, Hop WC.

[25]. Drogendijk AC, Huikeshoven FJ: The low transverse Pfannenstiel incision and the prevalence of incisional hernia and nerve entrapment. Ann Surg 1997;225:365-369.

[26]. Krahenbuhl L, Sclabas G, Wente MN, et al: Incidence, risk factors, and prevention of biliary tract injuries during laparoscopic cholecystectomy in Switzerland. World J Surg 2001; 25:1325-1330.

[27]. Burkitt G, Quick C, Gatt D. Essential surgery, 2nd edn. Oxford: Churchill Livingstone, 1995.

[28]. Grace PA, Borley N. Surgery at a glance. Oxford: Blackwell, 2006.

[29]. Intensive Care Society website. Levels of critical care for adult patients. Available from: www.ics.ac.uk/intensive_care_professional/standards_and_guidelines/levels_of_critical_care_for_ adult_patients. 